\title{
THE IMPACT OF EMULSIFICATION AND WHIPPING ON FAT CRYSTALLIZATION BEHAVIOR: A COMPARATIVE STUDY BETWEEN ANHYDROUS MILK FAT AND A LAURIC FAT
}

\author{
Petrut Raul Flaviu ${ }^{1}$, Christophe Blecker ${ }^{2}$, Vera Van Hoed ${ }^{3}$,Anne Dombree ${ }^{4}$, Sabine Danthine ${ }^{5}$ \\ ${ }^{1,2,5}$ Unité de Science des Aliments et Formulation, Gembloux Agro-Bio Tech, Université de Liège, Belgium \\ ${ }^{3,4}$ Puratos Group, Groot-Bijgaarden, Belgium
}

\begin{abstract}
In the present study, one commercial lauricfat $(L F)$ and one anhydrous milk fat (AMF) were compared for their behavior in three different states: bulk, $\mathrm{O} / \mathrm{W}$ emulsion and whipped cream. The objective of this work was to identify the crystallization and polymorphic behavior of the aforementioned fats, while pointing out the differences between the two fats, and for each of them, between the fat's bulk, $\mathrm{O} / \mathrm{W}$ emulsion and whipped cream state. For this purpose a combination of differential scanning calorimetry (DSC) stop\&return, pulsed nuclear magnetic resonance (p-NMR) and powder X-Ray diffraction (XRD) was employed. In the bulk phase, during crystallization under quiescent conditions, the two fats show a distinct thermal and polymorphic behavior. In this regards, the AMF would require a lower supercooling degree or a longer crystallization time compared to LF which showed little/no evolution during the isothermal crystallization. The XRD measurement revealed a mix of $\alpha$ and $\beta$ ' form for $L F$, all forms in a double chain lamellar structure (2L). Under the same conditions the bulk AMF was characterized by a $2 L \alpha+2 L \beta$ ' and in addition compared to the lauric fat, a $3 L \alpha$ form. The pointed differences exist between the two fats, mainly due to their chemical compositions. The emulsification/whipping did not affect the behavior of neither AMF nor LF. The lack of differences between bulk, O/W emulsion and whipped cream of the same fat upon DSC stop\&return disclose the presence of heterogeneous nucleation in all three states. Regardless the complexity of fat chemical composition, throughout obtaining $\mathrm{O} / \mathrm{W}$ food emulsion and/or structured creams the fat can be processed without altering its original properties.
\end{abstract}

Keywords: Bulk Fat, Emulsion, Whipped Cream, Crystallization, Heterogeneous Nucleation, Calorimetry, X-Ray Diffraction, Partial Coalescence

\section{INTRODUCTION}

Fat crystallization determines most of the physico-chemical properties and sensory attributes of the rich fat products such as oil-in-water emulsions and whipped creams. During processing, fat crystallization is used to modify or control the properties of the final products. In such systems, the fat crystallization can lead to a different nucleation mechanism compared to the bulk fat. This is a consequence of the emulsification process, where the fat is dispersed as fat droplets of different sizes, which impacts the supercooling degree needed to induce crystallization regardless the employed fat.

The solid fat functionality and oxidative stability are the main reasons that high melting fats are used in the detriment of oil [1]. These types of fats are suitable for the production of various foods due to their high end melting point and improved physicochemical properties (e.g. hardness, SFC). In various food systems the fat phase is found as the dispersed phase and is composed mainly by triacylglycerols (TAGs). The nature (i.e. animal, vegetal) of fatstrongly reflects on its properties as the fatty acids within the TAGs vary in chain length, composition, distribution and degree of saturation with fat's origin [2]. A highly used fat of animal nature for obtaining $\mathrm{O} / \mathrm{W}$ food emulsions, whipped topping and ice-cream is the anhydrous milk fat (AMF), while of vegetal origin the most implied in the formulation of these kind of food products are lauric fats (i.e. palm kernel oil).

The use of lauric fats (i.e. palm kernel oil) over the animal (milk) fat and other (conventional partially hydrogenated) oils is a continuously uprising trend in the food sector. This preference setin due to its heat stability, physicochemical properties, wide availability and other economic aspects. The lauric fats contain medium chain length TAGs similar to those found in the milk fat, which will ensure the $\beta$, crystalline form needed to provide a smooth texture, correct melting characteristics and mouth feel of the final product $[3,4]$. Thse fats rich in lauric acid, in particular, are commonly used for obtaining different $\mathrm{O} / \mathrm{W}$ emulsions, whipped topping, ice cream and spreads as crystallization will lead to the formation of a fat structure through a phenomenon called partial coalescence. Nonetheless the crystallization of fat, in particular, can be held responsible for positively or negatively changes in the mouth feel, stability, texture and appearance of the above mentioned food systems $[5,6,7]$. The crystallization of lauric fats is raising a lot of interest due to its wide area of application, thus various lauric fat fractions and blends were studied in their bulk phase $[4,8,9]$ and in the emulsified form due to their influence on the final properties of the system $[10,11,12]$. 
AMF is a highly complex fat system consisting of approximately $97 \%$ TAGs, which are making up the major components, while the minor components consist of free fatty acids, monoacylglycerols, diacylglycerols, free sterols and phospholipids. The complexity of AMF comes from the wide diversity of fatty acids which possess various chain lengths (C4 - C18), degree of saturation and distribution in regard to the glycerol head. While only 12 individual fatty acids are in a proportion larger than $1 \%$, more than 400 distinctive fatty acids were discovered in milk fat. With a higher saturated to unsaturated ratio, the saturated fatty acids make up $66 \%$, the mono-, di-, tri- and polyenoic acids represent $32.2 \%$, while the remaining content is attributed to branched acids and other acids [13]. The broad melting range, between $-40^{\circ} \mathrm{C}$ and $40^{\circ} \mathrm{C}$ makes the AMF desirable for the formulation of some food systems as a mixture of solid and liquid states exist side-by-side, while the same melting range makes it unsuitable for other applications $[14,15]$. Therefore the crystallization and thermal behavior of milk fat are complex processes which are highly studied in the literature, both in bulk state $[16,17,18]$ and emulsified state $[19,20,21]$.

It is known, however, that the emulsification changes the properties of the fat by altering the nucleation kinetics $[22,23]$. On one hand, the nucleation in the bulk fat can take place either via homogeneous or heterogeneous mechanism. The impurities present in the fat phase play an important role in the nucleation mechanism as in the absence of impurities the crystallization of fat take place via homogeneous nucleation, while heterogeneous nucleation is considered to be the main mechanism where impurities, surfactants, dust and other minor components are present. Nonetheless the nucleation mechanism is also influenced by the cooling rate and the ratio of catalytic impurities [24]. On the other hand, in the emulsified system the homogeneous nucleation is believed to occur as the fat is dispersed under the form of small droplets which are likely to contain none or insulated impurities. Other factors impacting the nucleation mechanism the droplets size and distribution, and the presence of different surfactants. For this reason it was suggested that in emulsion system where surfactants are present, fats could undergo heterogeneous nucleation as the surfactants can act as nucleation templates at $\mathrm{O} / \mathrm{W}$ interface [25].

The purpose of this study was to bring clarity on how the fat processing (i.e. emulsification, whipping) impacts the fats thermal and polymorphic behavior. AMF and LF were selected for emphasizing the differences between the different states (bulk, emulsion and whipped cream) due to their different chemical composition and crystallization behavior. To our knowledge no study compares the thermal and polymorphic behavior of the fats in the three states under the same processing and storage conditions. We demonstrate using microscopic, p-NMR, DSC and X-Ray approaches how the fat crystallization is affected by emulsification and further on by whipping. The results obtained in this study on a simple model could also be transferred to an industrial and more complex model.

\section{MATERIALS AND METHODS}

\subsection{Materials}

Anhydrous Milk Fat (AMF) was kindly supplied by CORMAN S.A. (Goé; Belgium) and the vegetable lauric fat (LF) was kindly provided by Puratos Group (GrootBijgaarden, Belgium), they were both used as received. The milk protein powder (BB powder) was also provided by CORMAN S.A. (Goé; Belgium).

\subsection{Emulsion and Whipped Cream Preparation}

A simple oil in water $(\mathrm{O} / \mathrm{W})$ emulsion model was developed at lab scale with a final concentration of $30 \%$ fat and $2 \%$ protein. A premix was prepared, by dispersing the BB powder in deionized water (Ultrapure water, Type 1) under magnetic stirring for 40 minutes at room temperature. The fats were completely melted, thus preventing the existence of any fat crystals. The melted fat was added to the premix and mixed by shearing with an Ultra-Turrax T-45 laboratory homogenizer (IKA, Staufen, Germany) at 10,000 rpm. The homogenization was conducted for 2 minutes at $75^{\circ} \mathrm{C}$ [26]. After emulsification, the emulsions were immediately placed at $4 \pm 0.5^{\circ} \mathrm{C}$ for $24 \mathrm{~h}$ prior to any investigations or whipping. Hereinafter the emulsions formulated with AMF will be referred as CAMF, while for emulsions formulated with LF as CLF.

The maturated emulsions were transferred into a precooled $\left(6 \pm 0.5^{\circ} \mathrm{C}\right)$ metal beaker and whipped using a Schlagsahne Prüfgerät (Elektronik Malente/Host, Germany) apparatus, equipped with a dual cylindrical whisker system which rotates with a constant $300 \mathrm{rpm}$. The consistency of cream during whipping can be monitored and recorded as a result of the work used to rotate the whips. The whipping was conducted for 2 minutes and the newly obtained whipped creams were further equilibrated at $4 \pm 0.5^{\circ} \mathrm{C}$ for 5 minutes prior to any investigations.

\subsection{Particle Size Distribution By Laser Light}

\section{Scattering}

The fat droplets size and distribution were assessed with a Malvern Mastersizer 2000 (Malvern Instruments, Malvern, UK), paired with the cell for liquid measurements (Hydro 2000S, Malvern Instruments, Malvern, UK). The measurements were conducted at room temperature using an obscuration of approx. $20 \%$ as described by Anihouvi et al. [12]. Different refractive indexes (RI) were inputted for AMF (1.462) and for LF (1.465), while a RI of 1.33 was implied for the dispersant. The results are the means of at least three measurements.

\subsection{Microstructure Investigation By Optical}

\section{Microscopy}

The microstructure of the samples was investigated with an optical microscope (Nikon Eclipse E400, Kanagawa, Japan) equipped with a digital camera (Nikon, DS-FI2, Kanagawa, Japan), a controller and a Peltier stage (PE60, Linkam 
Scientific Instruments Ltd., Surrey, UK). The samples were investigated at $4^{\circ} \mathrm{C}$ under polarized and normal light using a 10x, 20x and 40x magnification: (i) melted fat was place on a glass slide and covered with a glass cover slip and imaged at well-defined time interval during $4 \mathrm{~h}$; (ii) emulsions after a storage of $24 \mathrm{~h}$ at $4^{\circ} \mathrm{C}$ were diluted (10x dilution) with ultrapure water and placed on the glass slide and covered with the glass cover slip, then imaged; (iii) freshly prepared whipped cream was carefully place on the glass slide uniformly, in order to avoid the cream's structure breakage the glass cover slip was not placed. Images of the samples were taken and analyses with NIS Elements, V. 4.20 software (Nikon, Tokyo, Japan).

\subsection{Solid Fat Content (SFC) by NMR}

The SFC of the two fats in the three states (bulk, emulsion and whipped cream) was investigated by means of pulsed nuclear magnetic resonance (pNMR) using a Minispec mq20 minispec analyzer (Bruker, Germany). The NMR tubes were filled with sample up to a height of $4 \mathrm{~cm}$ as follows: (i) the bulk fat after its complete melting at $75^{\circ} \mathrm{C}$ was transferred into the NMR tube and right after stored at $4^{\circ} \mathrm{C}$ for $24 \mathrm{~h}$; (ii) freshly prepared emulsions are placed into NMR tubes and aged for $24 \mathrm{~h}$ at $4^{\circ} \mathrm{C}$ (iii) freshly created whipped creams are transferred carefully in the NMR tubes and equilibrated five minutes at $4^{\circ} \mathrm{C}$. Automatic calibration was daily made using a set of three standards with a SFC of $0.0,31.1$ and $74.8 \%$, respectively. Data are reported as the means of three measurements with the according standard deviation. For emulsions and whipped cream the following equation was used to calculate the SFC:

$$
\mathrm{SFC}=\left(\mathrm{SFC}_{\mathrm{e} / \mathrm{w}}-1.92\right) \times 3.33
$$

where $\mathrm{SFC}_{\mathrm{e}}-$ solid fat content of the emulsions and $\mathrm{SFC}_{\mathrm{w}}-$ solid fat content of the whipped cream.

\subsection{Thermal Analysis By Differential Scanning Calorimetry (DSC)}

The thermal investigations were conducted using a Q2000 DSC (TA Instruments, New Castle, DE, USA) coupled with a refrigeration cooling system (TA Instruments, New Castle, DE, USA). A modified indirect DSC method referred to as stop-and-return method was used [27]. The principle of the method is similar to the direct method, as the sample is completely melted (crystals removal) and then cooled to an isothermal crystallization temperature. The instrument was calibrated with indium and n-dodecane standards before measurement. Nitrogen was used as a purge gas.

The samples (2 - 4mg enclosed in hermetical aluminum) were investigated using a slow cooling rate $\left(1^{\circ} \mathrm{C} / \mathrm{min}\right)$ according to the next program: 1$)$ heating by $5^{\circ} \mathrm{C} / \mathrm{min}$ until $80^{\circ} \mathrm{C}$; 2) isothermal at $80^{\circ} \mathrm{C}$ for $5 \mathrm{~min} ; 3$ ) cooling by $1^{\circ} \mathrm{C} / \mathrm{min}$ until $4^{\circ} \mathrm{C}$; 4) isothermal for a time of $\mathrm{X}$ ( where $\mathrm{X}$ is $1 \mathrm{~min}$, $5 \mathrm{~min}, 10 \mathrm{~min}, 15 \mathrm{~min}, 30 \mathrm{~min}, 1 \mathrm{~h}, 4 \mathrm{~h}$ and $24 \mathrm{~h}$ ); 5) heating by $5^{\circ} \mathrm{C} / \mathrm{min}$ until $80^{\circ} \mathrm{C}$. The same program was applied for all the investigated samples in order to facilitate comparison. A linear baseline was used to integrate the melting peaks.
Universal Analysis Software version 4.2 (TA Instruments) was used to analyze the obtained melting profiles (e.g. peak temperature, peak area integration).

\subsection{Polymorphic Behavior By X-Ray Diffraction}

X-Ray powder diffraction (XRD) measurements were conducted to investigate TAG's longitudinal packing and crystalline form using a Bruker D8 Advance Diffractometer (Bruker, Germany) with $\mathrm{Cu} \mathrm{K} \alpha$ radiation $(\lambda=1.54178 \AA$, 40 $\mathrm{kV}, 30 \mathrm{~mA}$ ) equipped with an Anton Paar temperature control system composed of a TTK450 low temperature chamber, heating device (TCU 110 Temperature Control Unit) and liquid nitrogen cooling system (LNC Nitrogen Suction Equipment) (Anton Paar, Graz, Austria). Investigations were conducted on bulk, emulsion and whipped samples using two different detectors (LynxEye and VANTEC, Bruker, Germany) at long spacing (small angles, $1-10^{\circ} 2 \theta$ ) in order to identify the lamellar stacking and at short spacing (wide angles, $15-27^{\circ} 2 \theta$ ) to identify the subcell packing.

The temperature program used for the polymorphic investigations was the same as used for DSC investigations. The diffractograms obtained by XRD were analyzed and computed with the DIFFRAC.EVA (V.3.0, Bruker, Germany) software.

\section{RESULTS AND DISCUSSIONS}

\subsection{Emulsified Fat Droplets Size Distribution}

The crystallization of emulsified fats is known to be tightly linked to the fat droplets size and distribution [21]. The fat droplets average sizes of both the emulsions (CAMF and CLF) are presented in Table 1. The mean droplet range of 3$5 \mu \mathrm{m}$ is in agreement with the reported literature and is specific to the use of a high-speed homogenizer [28]. The emulsions formulated with both fats presented a bi-modal distribution (Figure 1). This distribution is linked to the existence of two distinctive populations, with individual droplets, as the addition of SDS is not observed to influence in any way the bi-modal distribution (results not shown here). The first population was observed between $0,5 \mu \mathrm{m}$ and $2 \mu \mathrm{m}$, while the second from $2 \mu \mathrm{m}$ to $15 \mu \mathrm{m}$. The fat droplets size distribution was then investigated after $24 \mathrm{~h}$ of maturation at $4^{\circ} \mathrm{C}$. CAMF showed the same droplet size distribution profile before and after maturation, with the same peaks and the same droplet populations. However in the case of CLF an increase of the first droplets population in the detriment of the second one was observed. This modification of small to large droplets population ratio can be attributed to the protein displacement from dropletsurface during crystallization, as hydrophobic moiety of protein has less affinity towards fat crystals [12]. This induces a disaggregation of fat droplets and thus a decrease of large droplets population. The phenomena could be more emphasized in the CLF than CAMF as more/larger fat crystals would be formed during crystallization of CLF, resulting in a higher degree of protein displacement. 
Table 1. Fat droplets size of the LF and AMF in emulsified and whipped state.

\begin{tabular}{lrrrrrr} 
& $\begin{array}{r}\text { D 4,3 } \\
{[\boldsymbol{\mu m}]}\end{array}$ & SD & $\begin{array}{r}\text { D 3,2 } \\
{[\boldsymbol{\mu m}]}\end{array}$ & SD & $\begin{array}{r}\mathbf{d ~ 0 , 5} \\
{[\boldsymbol{\mu m}]}\end{array}$ & SD \\
\hline CLF & 4.81 & 0.10 & 3.11 & 0.16 & 4.42 & 0.09 \\
\hline CAMF & 4.85 & 0.02 & 3.52 & 0.04 & 4.42 & 0.02 \\
\hline WCLF & 48.02 & 1.82 & 6.99 & 0.48 & 33.27 & 1.46 \\
\hline WCAMF & 21.13 & 1.06 & 6.01 & 0.22 & 11.65 & 1.70 \\
\hline
\end{tabular}

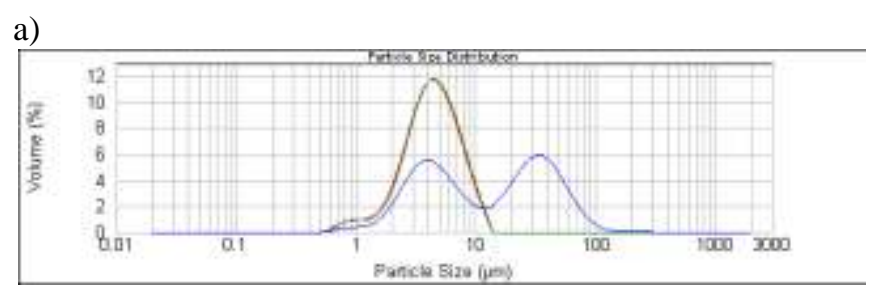

b)

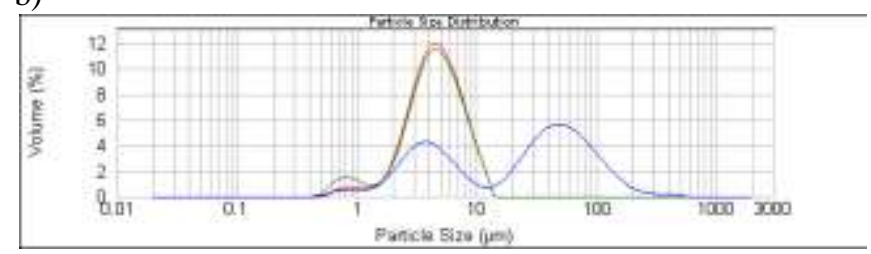

Figure 1. Particle size distribution of a) CAMF after recombination (red); CAMF after $24 \mathrm{~h}$ at $4^{\circ} \mathrm{C}$ (green) and

WCAMF (blue) right after whipping; b) CLF after recombination (red); CLF after $24 \mathrm{~h}$ at $4^{\circ} \mathrm{C}$ and WCLF (blue) right after whipping.

The fat droplets size and distribution was considered important also for the whipped creams, as different distributions could lead to discrepancies during the thermic/polymorphic investigations. For both formulations (WCAMF and WCLF) a tri-modal distribution of fat droplets was observed (Figure $\mathrm{X}$ ). The first two populations were the same as for CAMF and CLF. The third population of fat droplets, however, extends between $15 \mu \mathrm{m}$ and $150 \mu \mathrm{m}$. This population was observed to grow in the detriment of the other two populations. The appearance of a third population in WCAMF and WCLF was attributed to the occurrence of partial coalescence. It is known that partial coalescence during the whipping process is responsible for the fat network formation which will entrap the air bubbles [29]. Therefore, under the mechanical forces of whipping, the fat droplets from the first two populations come in close contact and form large fat aggregates. Under quiescent conditions partial coalescence does not occur in the present case, and hence for CAMF and CLF the third population of fat droplets is not observed. The two fats (AMF and LF) in the emulsified and whipped state have similar particle size and distribution, thus it can be expected that both will undergo the same crystallization mechanism. Any differences that can arise in terms of thermal and polymorphic behavior of CAMF, CLF, WCAMF and WCLF are expected to be independent of the fat droplets size and distribution.

\subsection{Solid Fat Content of the Three Systems (Bulk,} Emulsion, Whipped Cream)

The two bulk fats were subjected to an isothermal crystallization at $4^{\circ} \mathrm{C}$ for $24 \mathrm{~h}$, after this storage the SFC was measured by pNMR. A large difference was observed between the SFC (Table 2) of AMF and LF, 90.61\% $\% 0.16$ for $\mathrm{LF}$ and $54.36 \% \pm 0.22$ for AMF. The difference in SFC can be explained by the different chemical composition of the fats. On one hand the lauric fat used here is a fat with a high content of saturated medium and long chain fatty acids such as lauric acid (C12:0), myristic acid (C14:0) and stearic acid (18:0), with a relatively high melting temperature range $\left(44-70^{\circ} \mathrm{C}\right)$ [9]. On the other hand the AMF is a high complex fat containing a wide variety of fatty acids, with different chain length from which only $66.6 \%$ are saturated [13].

Table 2. Differences between AMF and LF in SFC levels in bulk, emulsified and whipped state (The SFC for emulsions and whipped creams were reported after integration for $100 \mathrm{~g}$ fat)

\begin{tabular}{lcc} 
& SFC [\%] & SD \\
\hline AMF & 54.36 & 0.22 \\
\hline CAMF & 52.40 & 0.11 \\
\hline WCAMF & 52.18 & 0.30 \\
\hline LF & 90.61 & 0.16 \\
\hline CLF & 89.88 & 0.22 \\
\hline WCLF & 89.52 & 0.19 \\
\hline
\end{tabular}

The emulsification process does not seem to affect the level of SFC after $24 \mathrm{~h}$ at $4^{\circ} \mathrm{C}$ in the case of $\mathrm{LF}$, as the recorded values for SFC are similar (Table 2). The similar SFC observed for both bulk and emulsion, can lead to the assumption that the same crystallization mechanism occurs in both states as a retardation of the crystallization (e.g. homogeneous nucleation) would result in a lower SFC for the same period of time, which is not the case here. A small difference $(\sim 2 \%)$ between the SFC recorded for the AMF and CAMF is observed. This tendency of lower SFC found in emulsion for AMF in comparison with the bulk was also previously reported in the literature $[22,21]$. It is, however, more probably that the difference arise from the mathematical model used for SFC calculation, as the same equation was used for both CAMF and CLF. Hence it was implied that the emulsification process does not affect the fats SFC level after a maturation of $24 \mathrm{~h}$ at $4^{\circ} \mathrm{C}$.

The whipping process (i.e. shearing forces) was not observed to have an influence on the SFC of neither one of the studied fats. The WCAMF and WCLF had the same solid content as CAMF and CLF with a SFC of $89.52 \%$ \pm 0.19 forWCLF and $52.18 \% \pm 0.30$ for WCAMF. 


\section{3 mICROSTRUCTURE INVESTIGATIONS}

The AMF and LF were cooled at $4^{\circ} \mathrm{C}$, kept isothermally and investigated for $24 \mathrm{~h}$ using PLM (Figure 2). In the case of AMF, during the first 4 hours, an evolution of crystals size and morphology is observed, whereas in the case of LF this evolution lacks (Figure 2). The milk fat crystals formed are smaller and fewer compared to the crystals formed in the LF. This could be explained by the different SFC observed for the two fats, as in the case of AMF more liquid fat is still present at $4^{\circ} \mathrm{C}$. The crystals morphology observed was a mixture of irregular spherulites and needle-like forms for $\mathrm{AMF}$, which could correspond to the hard fraction (stearin) and, respectively, to the soft fraction (olein) of the AMF. In the LF, the formed fat crystals were observed only under the form of dense irregularly spherulites having different sizes.

a)

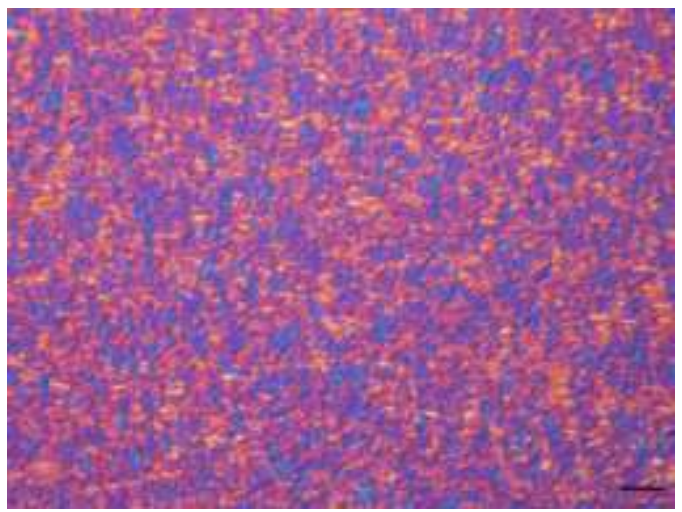

b)

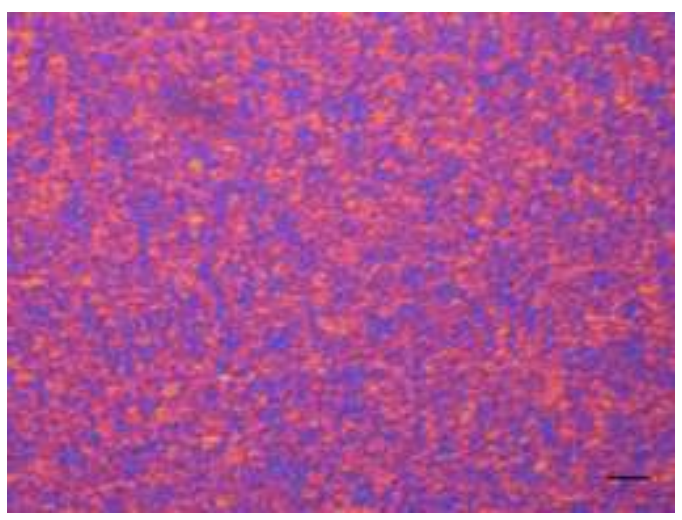

c)

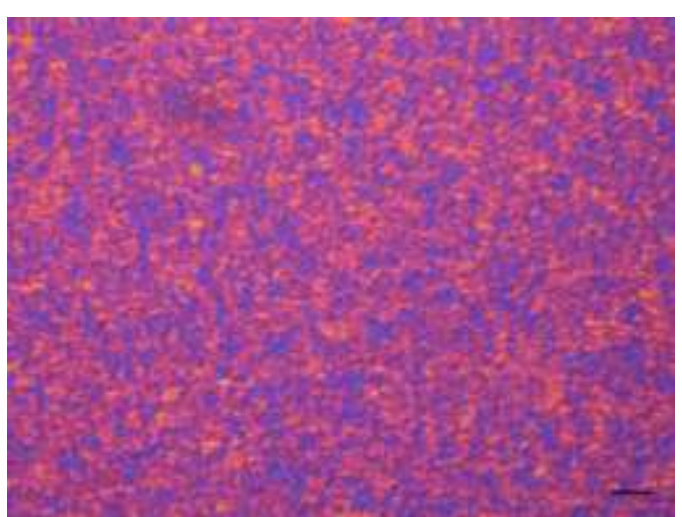

d)

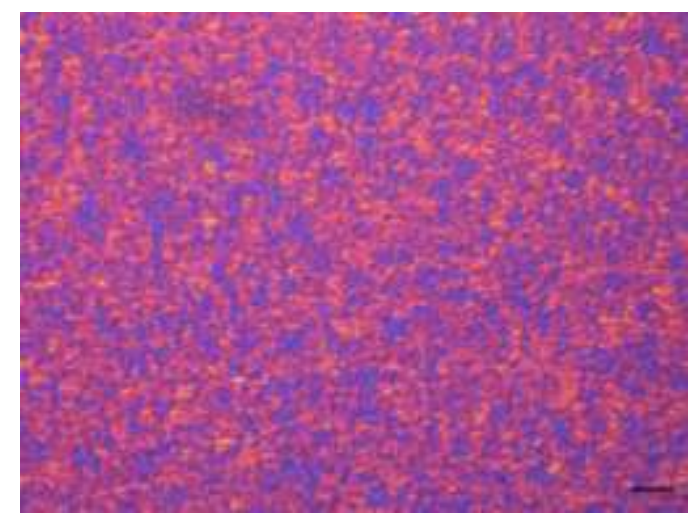

e)

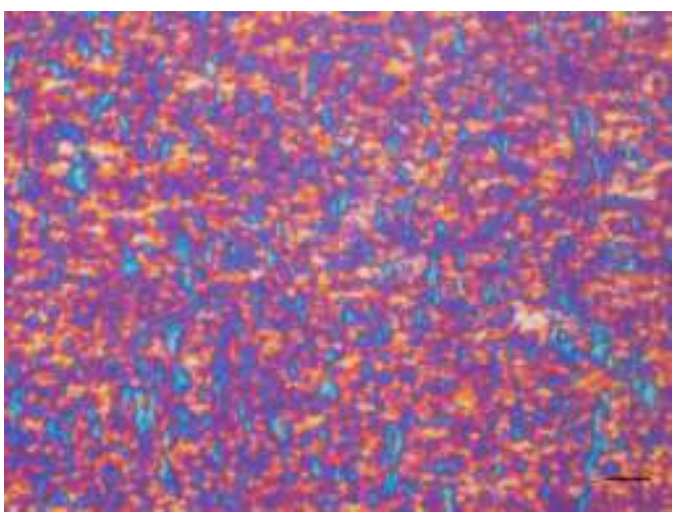

f)

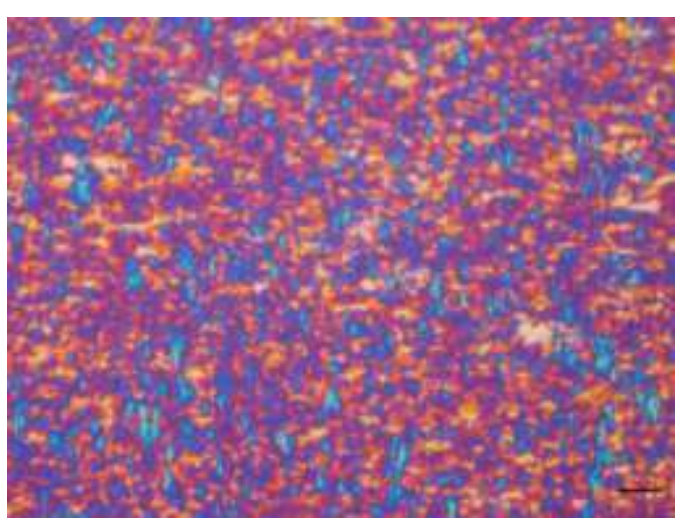

g)

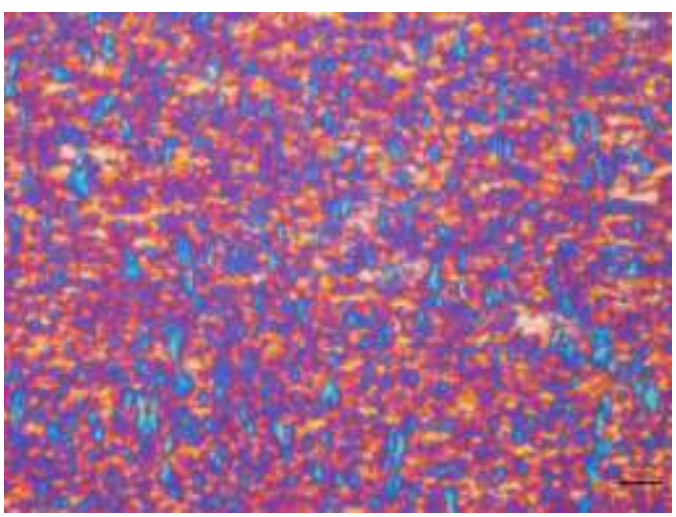


h)

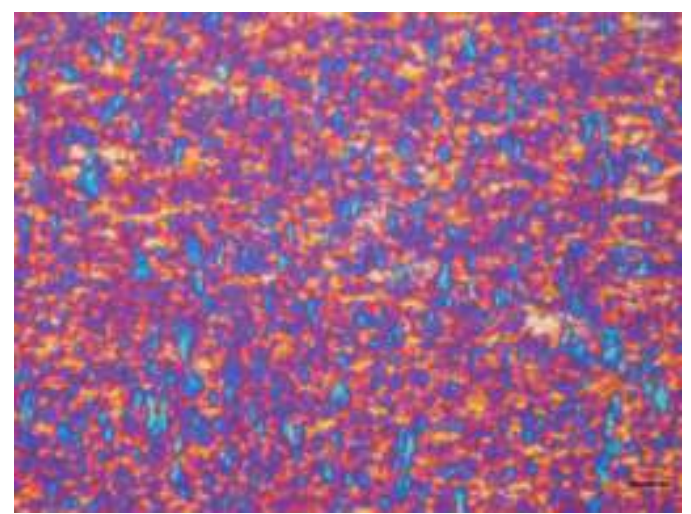

Figure 2. Fat crystals evolution during isothermal crystallization as a function of time, of AMF (a) after $1 \mathrm{~min}$, b) after $1 \mathrm{~h}, \mathrm{c}$ ) after $2 \mathrm{~h}, \mathrm{~d}$ ) after $4 \mathrm{~h}$ ) and of LF (e) after $1 \mathrm{~min}$, f) after $1 \mathrm{~h}, \mathrm{~g}$ ) after $2 \mathrm{~h}, \mathrm{~h}$ ) after $4 \mathrm{~h}$ under polarized light. Scale bar represents $20 \mu \mathrm{m}$

Nevertheless, in the emulsified state, the two investigated fats (CAMF and CLF) form similar crystals in term of morphology and arrangements (Figure 3). For both fats needle-like crystals of $\mathrm{N}, \mathrm{L}$ and $\mathrm{O}$ types were observed in the maturated emulsions, according to the classification done by Walstra P. [30]. The latter crystal type (O) was attributed to the small crystals formed within the droplets which were not birefringent, as the very small size of the formed crystals did not allowed the visualization of them. Due to the large variation in the crystals size found in the large droplets it is possible that what was observed to be in fact a sum of birefringences from several layered crystals one onto each other within the same droplet [19]. However, the crystals which occurred in the CLF were showed to deform the spherical shape of the CLF fat droplets to a larger extend compared to those present in the CAMF. Therefore differences could arise between the crystals formed by CLF and CAMF in terms type and arrangement for the very small crystal sizes which were not observed with the PLM.

a)

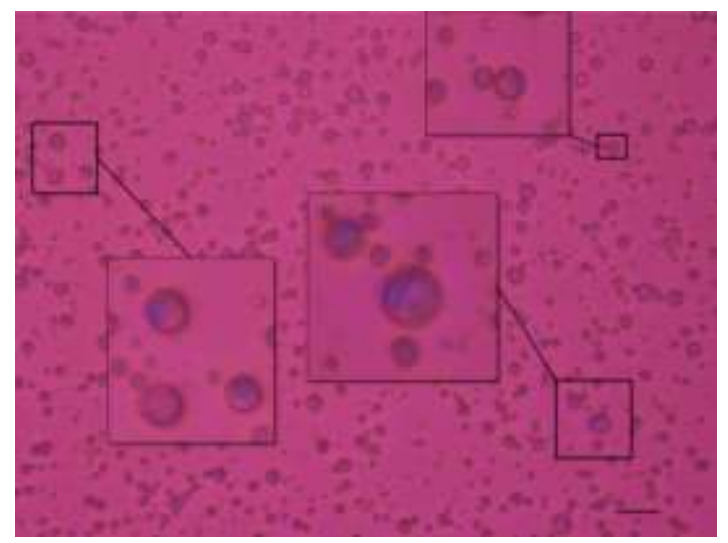

b)

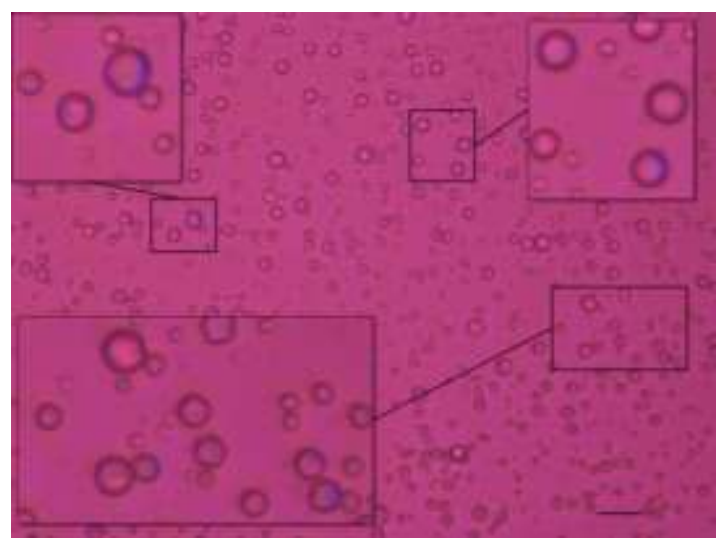

Figure 3. Fat crystals morphology and arrangements present in the CAMF (a) and CLF (b) dispersed fat droplets, observed under polarized light. Scale bar represents $20 \mu \mathrm{m}$

In the whipped state, the fat crystals were too small to be observed by PLM means at the implied conditions (Figure 4). Therefore only structural aspect of the fat network and aqueous phase were observed. WCAMF and WCLF formed well-structured systems with a fat network in which air was incorporated under the form of bubbles. The fat network formed in both creams is similar as the air bubbles present a monodisperse similar size distribution and a spherical shape form.

a)

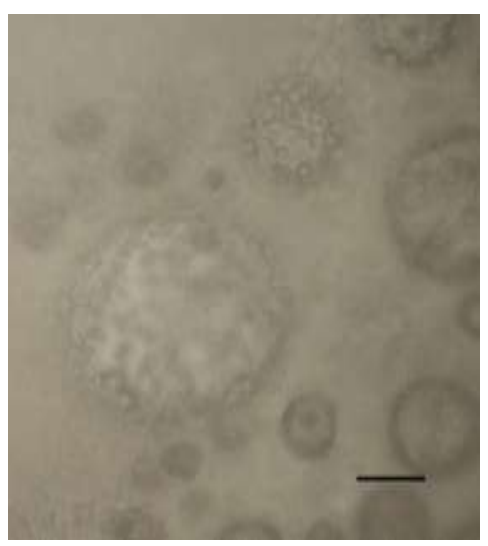

b)

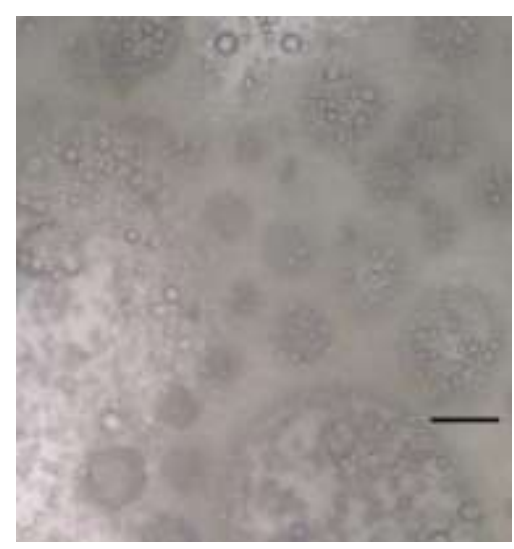

Figure 4. Micrographs of a) WCAMF and b) WCLF at $4^{\circ} \mathrm{C}$ right after whipping. 


\subsection{Thermal Behavior and Evolution During the}

\section{Isothermal Crystallization of Fats}

The two fats in their three different states were investigated by means of DSC in order to identify any possible differences of their thermal behavior (Figure 5). The measurements were conducted using the Stop\&Return method [27], with small modifications when investigating fats under bulk and emulsified states. The samples have to be stable during the temperature cycles, otherwise the obtained results could be altered. While for the bulk fat the stop-and-return method raises no problems, for emulsions and implicit for whipped creams destabilization will occur especially at low cooling rate [31]. Destabilization of fat, possibly due to partial coalescence, will lead to the formation of larger fat droplets during heating step, which will undergo a heterogeneous instead of homogeneous nucleation which is known to occur for small dispersed fat droplets. Therefore the onset crystallization temperature of sample will shift, being also possible to have an addition peak corresponding to the destabilized fat. In order to overcome this shortcoming of the method, different DSC pans were used for emulsions and whipped cream for each isothermal crystallization cycle. However, not using the same DSC pan during the entire cycle could lead to a poor repeatability and false differences between the different isothermal crystallization cycles [27]. Therefore the initial onset temperature at the beginning and at the end of melting/crystallization, the peak position and intensity obtained with all the pans used were overlaid for the sample. As the profiles overlaid thoroughly, it was concluded that any observed difference between the melting behaviors of a sample subjected to the isothermal crystallization as a function of time are actually due to the different behavior of sample rather than due to the sample preparation and manipulation.

Moreover, a comparison was made between the emulsions prepared and maturated outside DSC and the emulsions crystallized in the DSC during 24h (results not shown here). As the thermograms were highly similar it was concluded that the method is accurate and can be used for this study.

a)

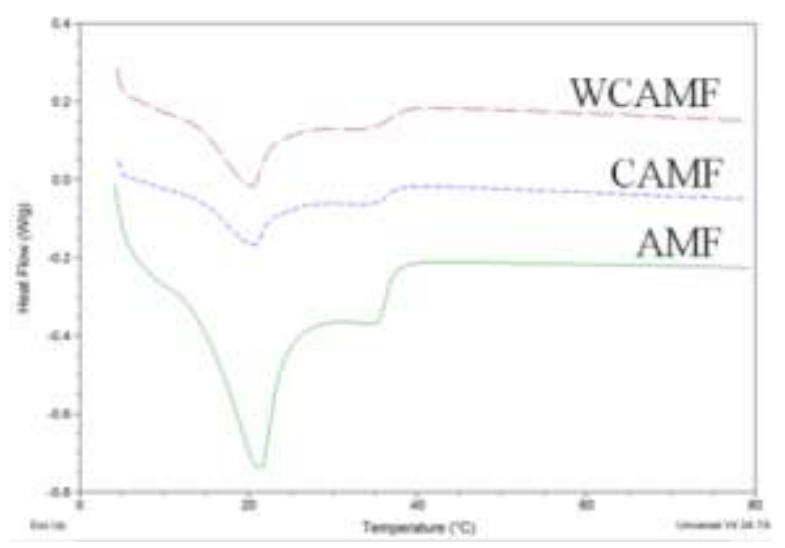

b)

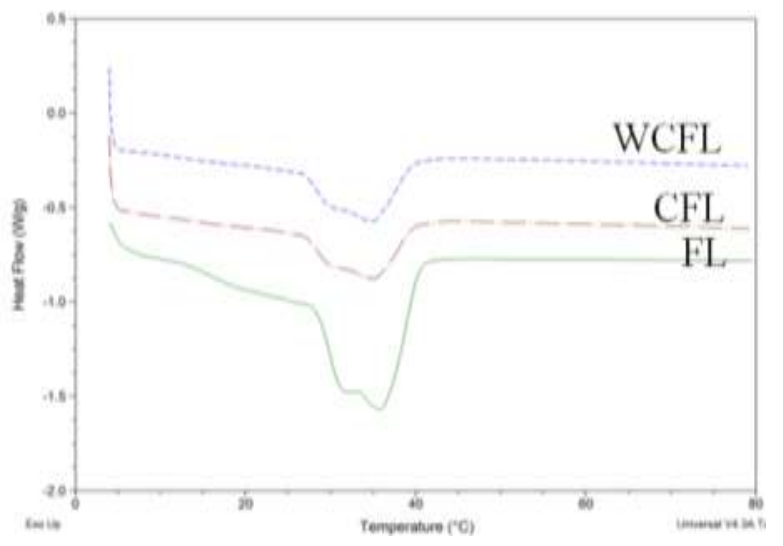

Figure 5. Melting thermograms for a) AMF and b) LF in all three states (bulk, emulsions and whipped) after $24 \mathrm{~h}$ crystallization.

The fats present under the whipped state would not make sense to be studied with a T-cycle method, as upon melting the partially coalesced fat structure, formed during whipping, is destroyed and the newly formed liquid fat droplets will undergo coalescence. Therefore, in the case of whipped system only one DSC measurements was conducted only right after the whipping process.

The melting thermograms of the AMF and LF obtained by DSC, for all three states (bulk, emulsified and whipped) are presented in the Figure 6. It was observed that the melting profiles of the AMF and LF differ for the same crystallization conditions. On one hand, the AMF was characterized by three major thermal events observable after the first isothermal crystallization ( $1 \mathrm{~min}$ at $4^{\circ} \mathrm{C}$ ) was applied. The three major thermal events remain characteristic until the $5^{\text {th }}$ cycle, where the sample was kept isothermally for $30 \mathrm{~min}$. At this point the melting behavior of the AMF is characterized only by two major thermal events, which remains characteristics until the end of the investigation $\left(24 \mathrm{~h}\right.$ at $\left.4^{\circ} \mathrm{C}\right)$. Even though the melting profiles are similar in terms of thermal events, the present peaks do not occur at the same temperature nor are of the same magnitude for each isothermal crystallization step. Therefore the crystallization of the AMF is considered to take place under a fractioned form, as the high melting fraction (HMF) of AMF crystallize first, in the detriment of low melting fraction (LMF). This crystallization particularity of AMF is in good agreement with the literature[17,27], as the present peaks shifted from a higher to a lower melting temperature. The increasing peak area with each isothermal crystallization step until 4h also pointed out the enhanced crystallization of the AMF, as more crystals are formed from the liquid (melted) phase. Nonetheless, another particularity of AMF's isothermal crystallization process was observed as the peaks were shifted towards higher melting temperatures, indicating possibly, a polymorphic transition of the formed fat crystals from a metastable form to a more stable form. 
a)

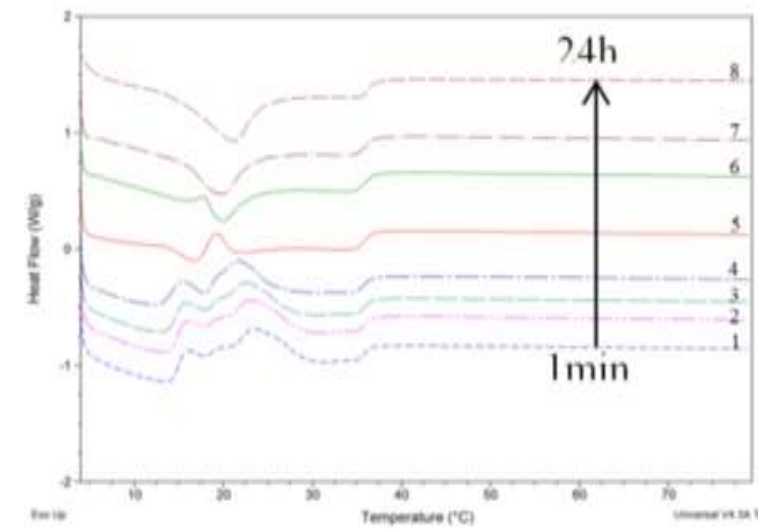

b)

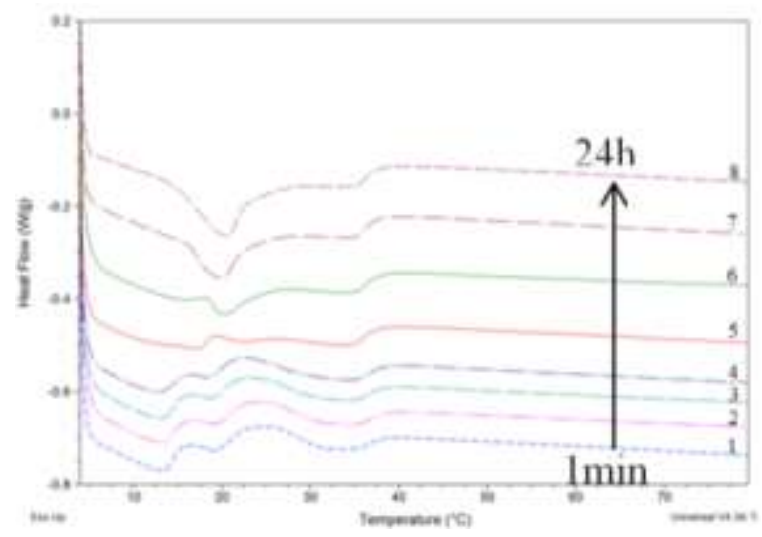

c)

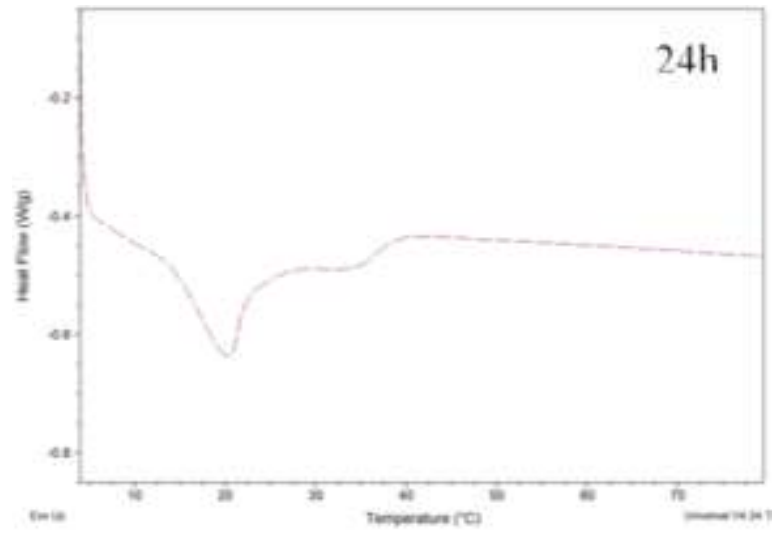

d)

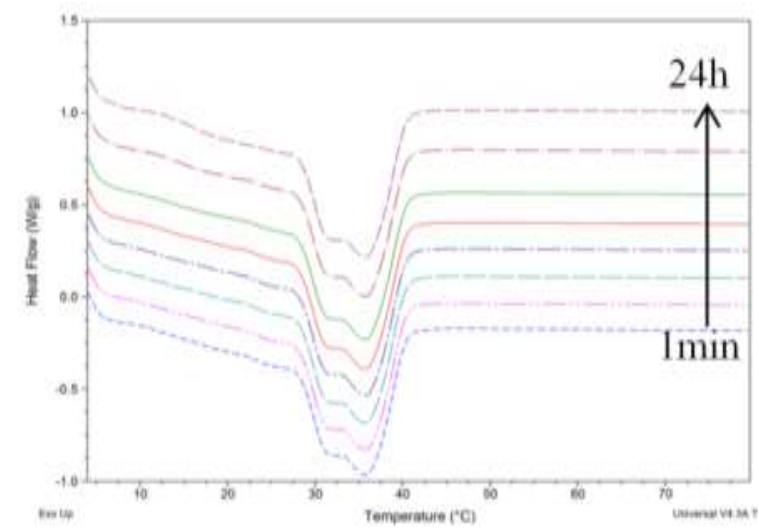

e)

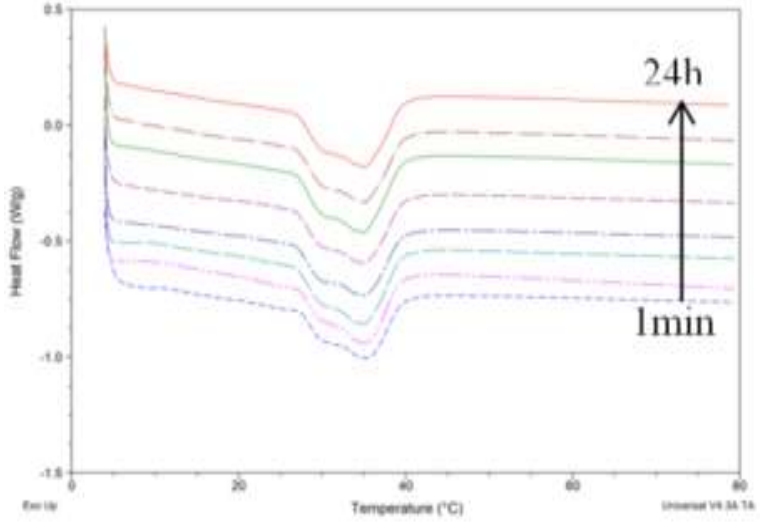

f)

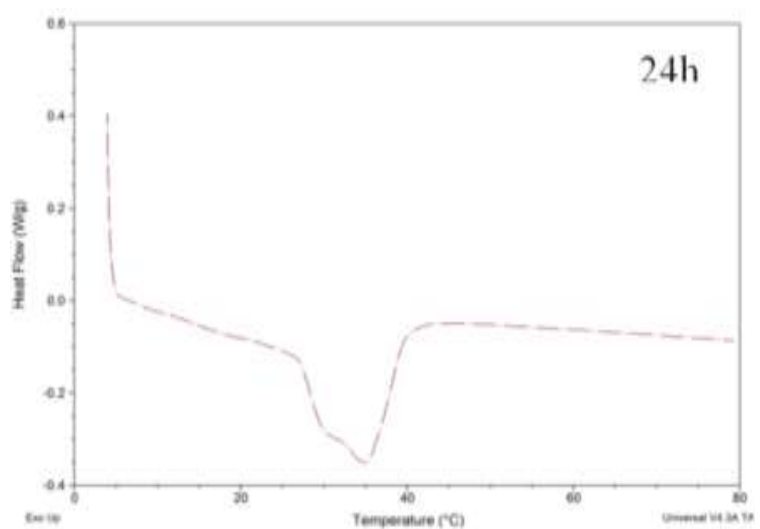

Figure 6. Stop\&Return DSC melting thermograms from $1 \mathrm{~min}$ to $24 \mathrm{~h}$ for a)AMF, b) CAMF, d)LF, e)CLF and after whipping for c)WCAMF and f)WCLF, where 1) $1 \mathrm{~min}$; 2) 5 min; 3) 10min; 4) 15min; 5) 30min; 6) $1 \mathrm{~h}$; 7) 4h and 8) $24 \mathrm{~h}$.

On the other hand, the LF showed similar melting behavior (Fig. 6d) throughout the entire period of isothermal crystallization. Two major thermal events were observed. The two peaks were present from the very beginning of the crystallization $\left(1 \mathrm{~min}\right.$ at $4^{\circ} \mathrm{C}$ ) and remain unchanged until the end of the investigation $\left(24 \mathrm{~h}\right.$ at $\left.4^{\circ} \mathrm{C}\right)$, within a narrower melting range compared to AMF. Another difference in terms of isothermal crystallization between AMF and of LF is that, in the latter case the crystallization did not occur in a fractionated way as the peak did not shift to lower temperatures. This can be explained by the chemical composition of the two fats, which is highly complex in the case of AMF and less diverse in terms of FA in the case of lauric fats. Nonetheless the LMF/HMF ratio difference between the LF and AMF could explain the faster and greater crystallization of the first, as within the same crystallization condition (i.e. cooling rate) the latter will require a higher supercooling. The two observed peaks in melting profile of the LF were attributed to the crystallization of LMMF and HMF.

According to a wide spread belief, the crystallization of fat in its bulk state occurs differently from its emulsified state $[32,33,34,35]$ as the crystallization of fat present in emulsion under the form of disperse droplets requires higher supercooling [19], depending on the fat droplets size. 
Therefore it would be expected that the emulsified fat crystallizes slower and to a lesser extend as compared to its bulk state. However both emulsions (CAMF and CLF) investigated in this paper showed highly similar profiles (Fig. 6b and Fig. 6e), with the same number of peaks, the same evolution across the investigated isothermal crystallization time period, with similar melting range and peak temperatures (Table 3 ) as in the bulk. In the case of CAMF, the crystallization can be divided in two major parts, as in bulk. In the first part, the fractionated crystallization is observed while the second part corresponds, presumably to a polymorphic transition of the metastable polymorphic form. For the CLF, a fractionated crystallization cannot be taken into consideration, but a polymorphic transition is still believed to take place also in this case, as small variations in peak shape could be observed. In both cases a reduction of peak magnitude in the cases of emulsified fat can be observed. This difference is not related to the crystallization behavior of fat, as it could be explained by the different amount of fat subjected to investigation in bulk and emulsion.

Table 3. Temperatures ranges observed for each major thermal event $\left(T_{1}, T_{2}, T_{3}\right)$ and the complete melting $\left(T_{m}\right)$ during the isothermal crystallization of the two fats in the 3 states, where the temperatures for WCAMF and WCLF are reported only for the melting profile obtain after whipping.

\begin{tabular}{lcrcr} 
& $\mathbf{T}_{\mathbf{1}}\left[{ }^{0} \mathbf{C}\right]$ & $\mathbf{T}_{\mathbf{2}}\left[{ }^{\circ} \mathbf{C}\right]$ & $\mathbf{T}_{\mathbf{3}}\left[{ }^{\circ} \mathbf{C}\right]$ & $\mathbf{T}_{\mathbf{m}}\left[{ }^{\circ} \mathbf{C}\right]$ \\
\hline AMF & $12.90-13.77$ & $17.39-21.14$ & $26.56-29.91$ & $37.34-37.61$ \\
\hline $\mathbf{L F}$ & $31.55-31.75$ & $35.72-36.04$ & - & $41.66-41.90$ \\
\hline $\mathbf{C A M F}$ & $13.02-13.48$ & $17.68-20.56$ & $26.80-30.82$ & $39.28-39.55$ \\
\hline $\mathbf{C L F}$ & $30.49-30.75$ & $34.31-34.64$ & - & $42.29-42.66$ \\
\hline WCAMF & - & 20.37 & 28.52 & 39.72 \\
\hline WCLF & 30.82 & 34.78 & - & 42.56 \\
\hline
\end{tabular}

Having the same crystallization behavior in both, bulk and emulsion was linked only to the applied cooling rate $[19,20]$ and to the fat droplets size [11,21]. However based on the present fat crystallization cooling rate $\left(-1^{\circ} \mathrm{C} / \mathrm{min}\right)$ and on the fat droplets size $(\sim 3.5 \mu \mathrm{m})$, it is more convenient to assume that these attributes are not individually responsible for the similarities between bulk and emulsion crystallization, but rather the appropriate combination of the two. Therefore applying a high-intermediate cooling rate to emulsions containing the fat phase dispersed in sufficiently large droplets will lead to a crystallization mechanism similar with the one occurring in the bulk state.

The melting behavior of the fats in the whipped state (Figure 6c and 6f), WCAMF and WCLF, does not differ from the melting profile of the previously studied AMF, LF, CAMF and CLF after a isothermal crystallization for $24 \mathrm{~h}$. The mechanical forces which act upon the fat during the whipping process do not seem to affect in any way the thermal behavior of the WCAMF and WCLF. The melting range, peak position and magnitude were of similar features as of the previously investigated states of fats.

In order to validate the hypothesis formulated in this part, implying the polymorphic transitions that could take place for both fats, an X-Ray investigation was conducted.

\subsection{Structural Investigations and Polymorphic}

\section{Evolution}

The XRD patterns of AMF and LF (Figure 7) were investigated at both wide (WAXD) and small-angle (SAXD). In the beginning of the measurement it was ensured that all the samples were completely melted, therefore no diffraction peaks were recorded at SAXD, while at WAXD only the typical hump given by the liquid phase at $4.5 \AA$ was observed [36]. In the case of AMF, it was observed that the crystallization occurs around $16^{\circ} \mathrm{C}$ with the first appearance of three individual peaks at SAXD, at $44.51 \AA$ corresponding to a double chain-length $\left(2 \mathrm{~L}_{1}\right)$ stacking of the TAG, at $40.6 \AA$ corresponding to second $2 \mathrm{~L}_{2}$ stacking and at $35.34 \AA$, respectively, which corresponds to a $3 \mathrm{~L}_{1}$ stacking $[37,38]$. The latter one is considered to be a second order peak of the original $3 \mathrm{~L}$ peak which would appear at $70.68 \AA$, indicating the actual thickness of the layer (the used X-Ray configuration did not allowed the visualization of the original peak). The magnitude of the three identified peaks was different across the investigated range of temperature and time. In the first part, where the crystallization is initiated, the peaks corresponding to $2 \mathrm{~L}$ stacking were observed to be larger than the one corresponding to $3 \mathrm{~L}$. This domain corresponds in fact to the crystallization of the HMF present in the AMF, as it is know that TGA having similar hydrocarbon tails in composition and length will usually organize under a 2L stacking [39]. However, as the crystallization of the TGA advances the $3 \mathrm{~L}_{1}$ peak increases and overpassed in magnitude the $2 \mathrm{~L}$ peaks. Whereas, in this step in was considered that more MMF and LMF crystallized, as the TGA in this case have different fatty acids moieties composing the tail which lead to the occurrence of the 3L longitudinal packing [39]. In a third domain, the second identified $2 \mathrm{~L}_{2}$ peak was observed to increase greatly in magnitude in the detriment of the other two peaks. This last step was seen as a polymorphic transition of metastable peaks into a more stable configuration, represented here by the $2 \mathrm{~L}_{2}$ peak observed at $40.6 \AA$. 
a)

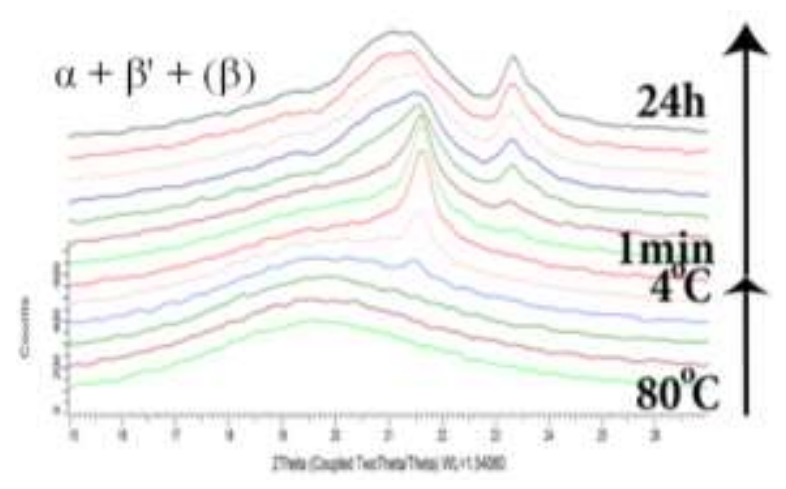

b)

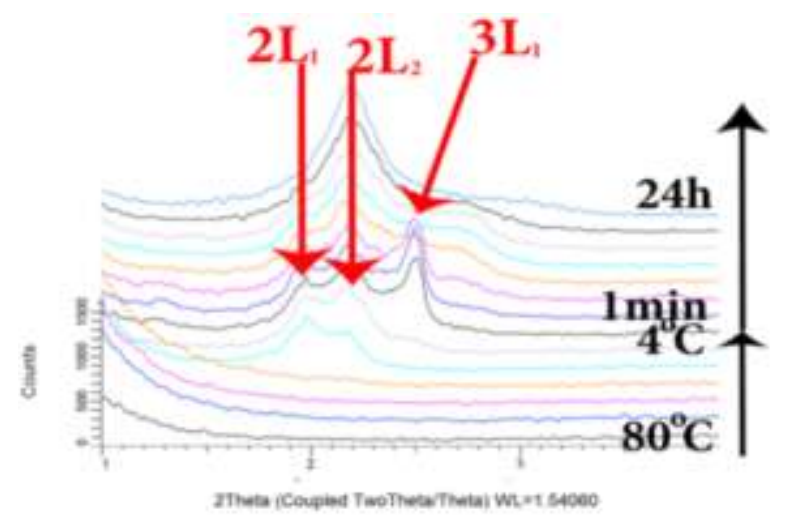

c)

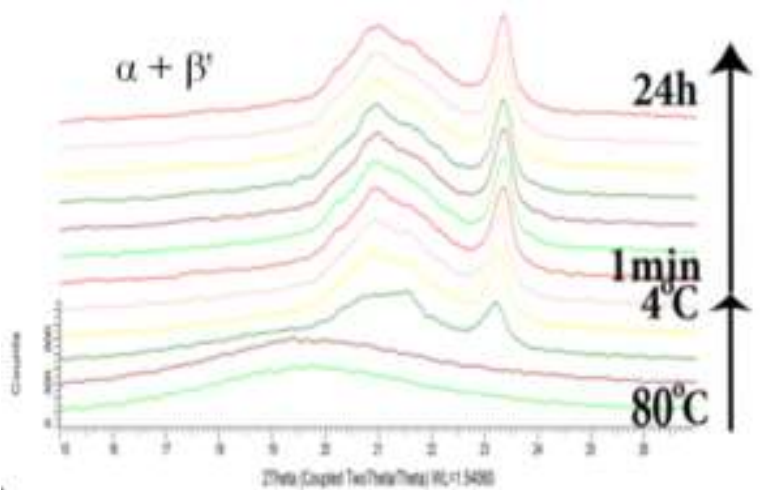

d)

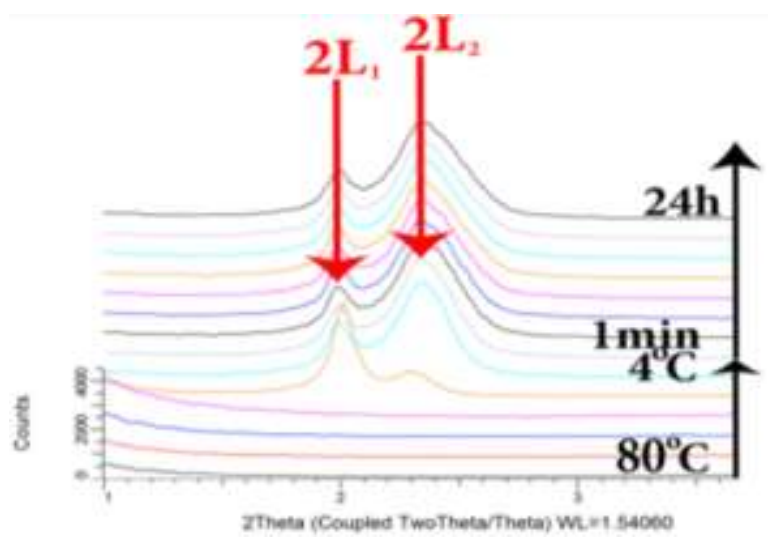

Figure 7. Polymorphic evolution and behaviour of AMF short spacing (a), long spacing (b) and LF short spacing (c), long spacing (d) upon cooling and isothemal crystallization.
At WAXD, the first peak identified at $4.13 \AA$ was attributed to a hexagonal packing of TGA chains, known as the metastable polymorphic form $\alpha$ [38]. The other two peaks observed at $3.82 \AA$ and $4.22 \AA$ were identified as the more stable orthorhombic chain packing corresponding to the $\beta$ ' polymorphic form. The concomitant formation of $\alpha$ and $\beta$, polymorph can be due to the cooling rate chosen in the present study. Hence at high cooling rate the AMF crystallizes under $\alpha$ polymorphs in a first step, while the $\beta$, polymorph appears after the corresponding induction time was overcome and as an result of the $\alpha \rightarrow \beta$ 'transition $[20,40]$. Based on the peaks magnitude and their evolution along the crystallization, the polymorphic organizations $2 \mathrm{~L}_{1}$ and to the $3 \mathrm{~L}_{1}$ were attributed to the $\alpha$ form. Further on the $2 \mathrm{~L}_{2}$ was attributed to the $\beta$ ' form. The attribution was done as the peaks corresponding to $2 \mathrm{~L}_{1}$ and $3 \mathrm{~L}_{1}$ increased in intensity for the first part of the crystallization and afterwards decreased in the favor of other, as in WADX the $\alpha$ polymorph increased at the beginning of the crystallization and decreasing in the second part in the favor of $\beta$, polymorph. This also explains the polymorphic transition seen in the last part of crystallization where the formed crystals tend towards a more stable form, thus undergoing an $\alpha \rightarrow \beta$ ' transition. After $4 \mathrm{~h}$ and $24 \mathrm{~h}$ of isothermal crystallization, traces of $\beta$ were also observed, besides the already mentioned polymorphs. Nonetheless, both polymorphic forms (i.e. $\alpha, \beta$ ') with their corresponding organizations were observed until the end of the investigation, suggesting that a complete transition does not take place within the investigated crystallization period.

On the other hand, it is worth noticing that the crystallization of LF was observed to start around $21^{\circ} \mathrm{C}$, with the first appearance of the well delimited, individual peaks in the SAXD. This observation is in good agreement with the results presented by DSC, where it was shown that that LF has a narrow melting range than the AMF, which will indirectly lead to an earlier crystallization of LF TGAs. The first peak appeared at $44.05 \AA$ and it was, of a higher magnitude than the second peak, which was observed at $37.89 \AA$. This was only observed for the beginning of the LF crystallization, as when reaching $16^{\circ} \mathrm{C}$ this magnitude proportion shift in the favors of the second peak. No evolution of the peaks intensity or position was further observed until the end of the investigated period of isothermal crystallization at $4^{\circ} \mathrm{C}$. Both observed peaks were attributed to a double chain length stacking (2L), as this kind of organization has a characteristic value comprised between 30 and $50 \AA[12,37]$. However, no $3 \mathrm{~L}$ organization as in the case of AMF was observed. This could be explained by the LF composition, which in most part comprise of trisaturated TAG, which along with the long-chain and high-melting TAG are known to be more likely organized under a $2 \mathrm{~L}$ structure $[9,37]$. Contrary to AMF, no evolution of the peaks throughout the isothermal crystallization was observed in the case of LF. This observation confirms the results obtained by DSC for LF, as no noticeable thermal or polymorphic transition was observed across the investigated period of time. The chemical composition difference between the two investigated fats also explain this discrepancy, as the high content in HMF with a narrow 
range of FA will lead to an earlier and faster crystallization in the case of LF compared to AMF. Therefore two $2 \mathrm{~L}$ structures identified for LF, coexists throughout the entire isothermal crystallization domain.

When investigating the WAXD, the peak noticed at $4.12 \AA$ was characteristic to $\alpha$ polymorphic form. The other two peaks observed at $3.82 \AA$ and $4.23 \AA$ were recognize as characteristics to $\beta$ ' polymorphic form $[41,42]$. Here, as in the case of AMF, both crystal varieties were present from the beginning of the crystallization until the end of the investigated time period. Nonetheless, at the initiation of crystallization, the $\alpha$ polymorph was more present, while as the crystallization advances an increasing of the $\beta$, polymorph is observed, in the detriment of $\alpha$ form. This is due to the polymorphic transition from the $\alpha$ to the $\beta$, $[3,34]$. After this transition, the presence of the $\alpha$ polymorph is quite difficult to follow using short spacing alone, as the peak at $4.23 \AA$, corresponding to $\beta$ ' is getting wider and higher in intensity, therefore incorporating the peak at 4.12 $\AA$, corresponding to $\alpha$. The $\alpha$ polymorph is associated with the first $2 \mathrm{~L}$ organization observed at $44.05 \AA$ in the long spacing, as it had the same evolution along within the recorded XRD pattern for crystallization. Therefore, $\alpha$ form was monitored using the long spacing and its presence until the end was confirmed by the $2 \mathrm{~L}$ organization peak in the SAXD. Implicitly the second $2 \mathrm{~L}$ organization, notice in the SAXD for LF, was attributed to the $\beta$ ' polymorphs. The lack of polymorphic evolution in the case of LF is supported by the DSC data, whereas the two major thermal events recorded with the DSC can be attributed to the melting of the $\alpha 2 \mathrm{~L}$ and $\beta$ ' $2 \mathrm{~L}$, respectively, as no polymorphic transition was recorded upon melting (results not shown here). The coexistence of both polymorphs from the start of crystallization could be linked to the intermediate cooling rate chosen for the present study, as at higher cooling rate the presence of only $\alpha$ in the beginning was reported $[2,34]$ while at slower cooling rate the presence of only $\beta$ ' was observed [9]. Nonetheless, in the case of LF no (traces) $\beta$ polymorph formations were observed at the end of the investigated period of time for the isothermal crystallization, as lauric fats tend to pack into $\beta$ ' as form of stability $[9,43]$.

Both fats in their emulsified state, CAMF and CLF (Figure 8), have similar polymorphic behaviors upon crystallization as observed in their bulk state. The crystals are observed to start around $16^{\circ} \mathrm{C}$ for CAMF and, $21^{\circ} \mathrm{C}$ for CLF. As in the bulk state, three different organization are observed in the case of CAMF, two $2 \mathrm{~L}$ and a $3 \mathrm{~L}$ chain length organization of the TGA, with an $\alpha$ and $\beta$ ' polymorphic forms, while for CLF only two chain organizations were observed, two $2 \mathrm{~L}$, with the same polymorphic forms, $\alpha$ and $\beta$ '. Nonetheless a crystallization particularity aside from the previous reported results $[19,20,44]$ was observed, as for both fats the appearance of $\alpha$ and $\beta$ ' polymorphic forms occurred simultaneous at the beginning of the crystallization and not individually with the appearance of $\alpha$ polymorphs first and then $\beta$ ' polymorphic forms appearing just as a results of the $\alpha \rightarrow \beta$ ' transition upon further cooling or crystallization. This type of behavior could be explained, at least partially, by the different cooling rate and fat droplet size used in the present research, as it is know that the cooling rate and droplets size can greatly influence the polymorphic form of the emulsified fat $[21,42]$. The $\alpha \rightarrow \beta$ ' transition is more emphasized for CAMF during the isothermal crystallization period, than in the case of CLF, as observed also in the bulk state. The attained polymorphic structure of the CAMF and CLF show, in agreement with DSC thermograms, that the crystallization of the fat in their emulsified state undergoes the same mechanism as in the bulk state, more than that, even the nucleation occurring at the same rate for AMF, LF, CAMF and CLF.

a)

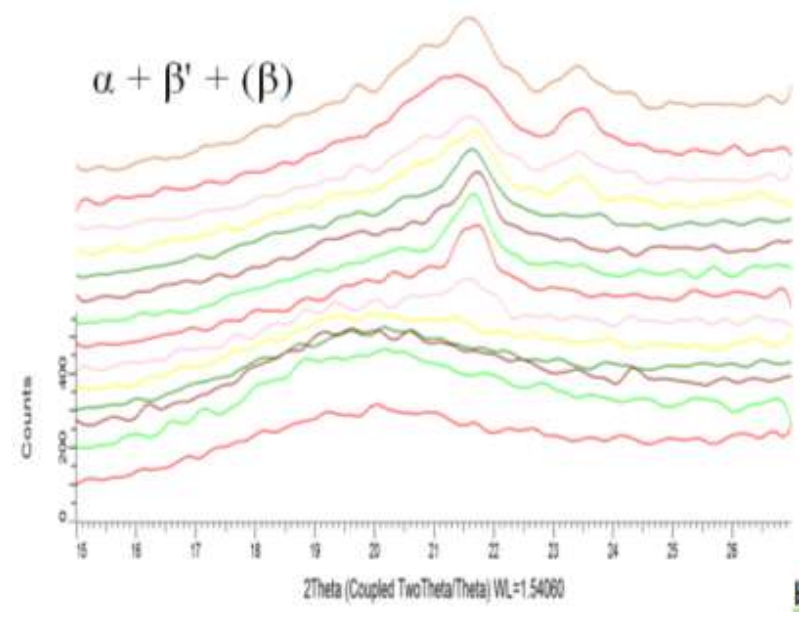

b)

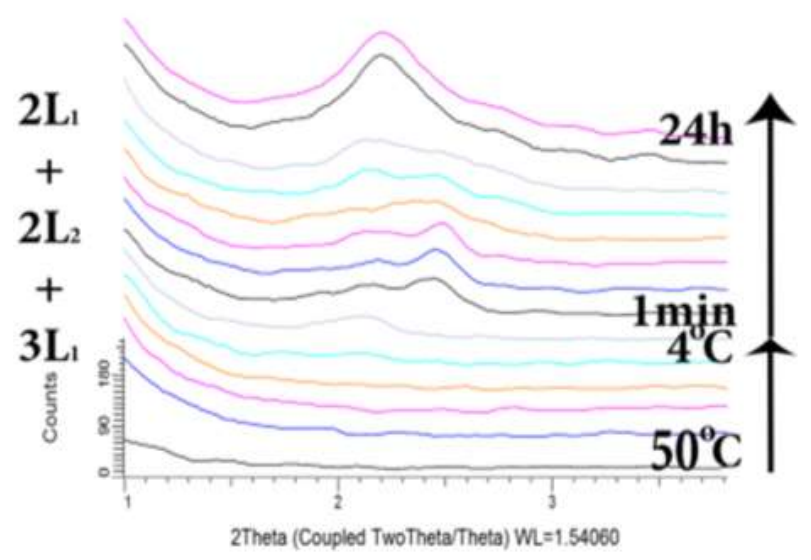

c)

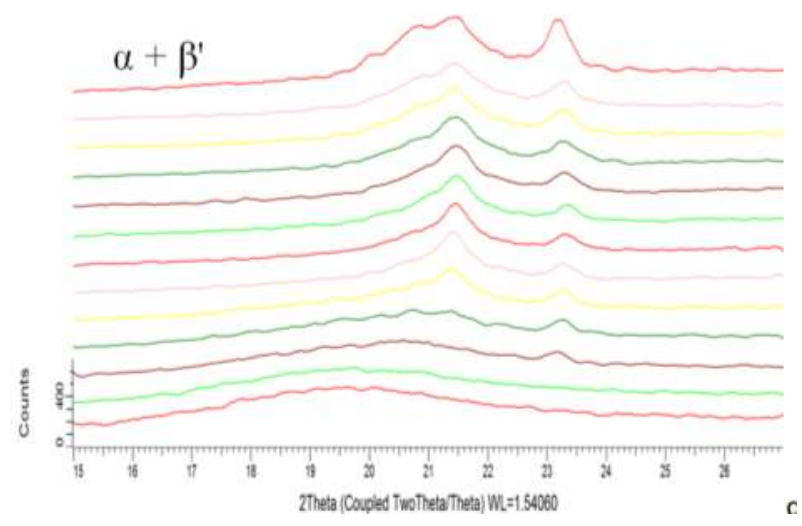


d)

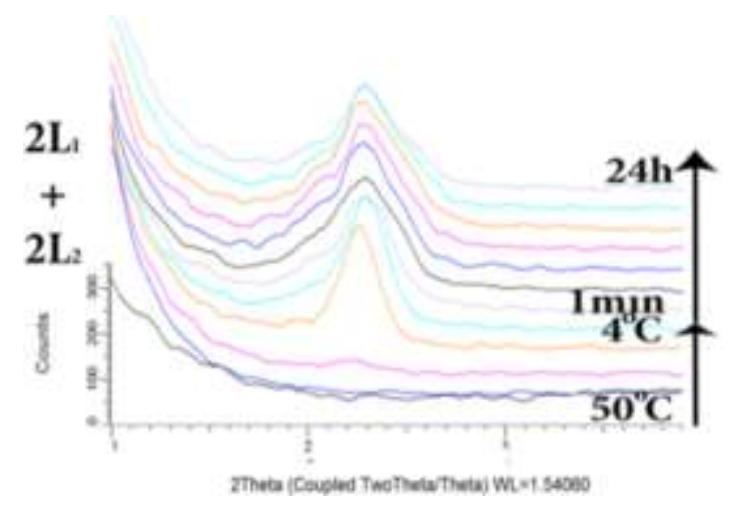

Figure 8. Polymorphic evolution and behaviour of CAMF short spacing (a), long spacing (b) and CLF short spacing

(c), long spacing (d) upon cooling and isothemal crystallization.

In their whipped state, WCAMF and WCLF (Figure 9), showed the same polymorphic behavior as in the bulk and emulsion state. The WCAMF was characterized by a $\alpha 2 \mathrm{~L}+$ $\alpha 3 \mathrm{~L}+\beta$ ' $2 \mathrm{~L}$ with traces of $\beta$, as previously seen for the other states, while for WCLF a polymorphic structure of $\alpha 2 \mathrm{~L}+$ $\beta$ '2L was observed. The mechanical forces applied during the whipping of the maturated emulsion did not seem to alter the polymorphic structure of WCAMF and WCLF, as the structure is the same with the one of CAMF and CLF, respectively, observed after an isothermal crystallization for 24h. Moreover the ratio between the observed peaks corresponding to the different polymorphic forms are highly similar with those noticed in for CAMF and CLF, indicating that the $\alpha \rightarrow \beta$ ' transition occurred in the same way as in the bulk and emulsified form, with similar contents of $\alpha$ and $\beta$ ' polymorphic forms.

a)

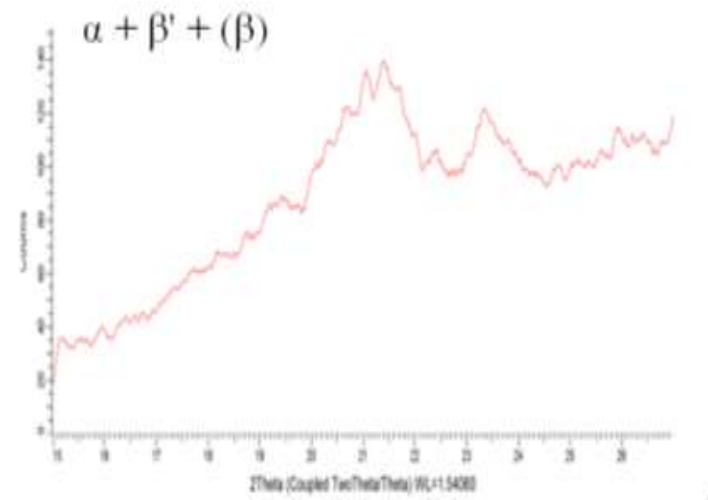

b)

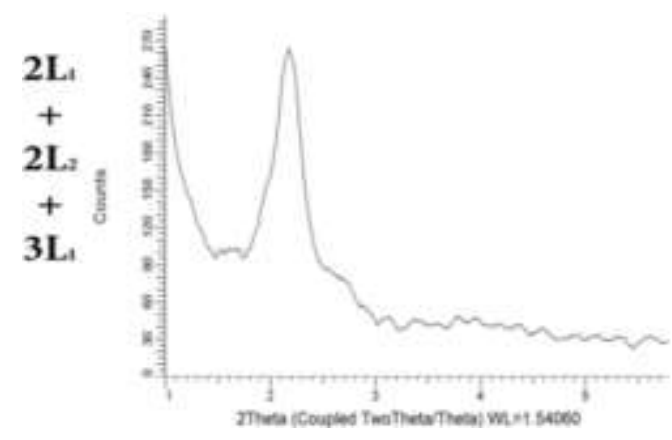

c)

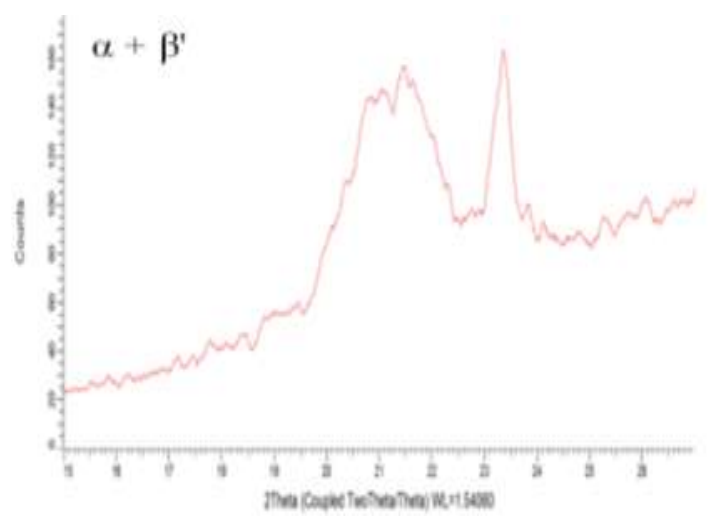

d)

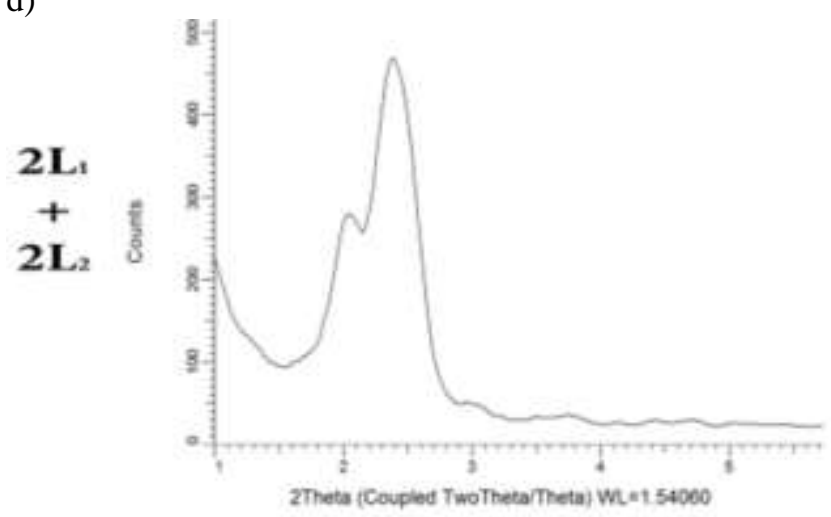

Figure 9. Polymorphic behaviour of WCAMF short spacing (a), long spacing (b) and WCLF short spacing (c), long spacing (d) after the whipping.

\section{CONCLUSIONS}

A narrow range of FA linked with a lower degree of supercooling could lead in achieving a complete crystallization under a stable configuration faster than in the case of a complex chemical composition, as in the case of AMF. The TGA chain length and composition may be responsible for the formation of different polymorphic organization such as $2 \mathrm{~L}$ and $3 \mathrm{~L}$ under the same crystallization conditions, while dictating possibly also the magnitude of the polymorphic transition that occurs during and isothermal crystallization.

Both investigated fats were observed to have highly similar thermal and polymorphic behaviors upon crystallization, in all three states. Therefore, it is legit to conclude that both fats undergo the same crystallization mechanism regardless the fat's state, with the applied crystallization and emulsification conditions. Moreover, due to the different chemical composition of the two investigated fats, it is believed that applying an optimal combination of an intermediate cooling rate and to an emulsion with relatively large fat droplets $(\sim 3.5 \mu \mathrm{m})$, will allow the emulsified fat to undergo a heterogeneous nucleation with the same/highly similar nucleation rates, as observed in the case of bulk fats. Therefore in all three states the formation of fat crystals was observed to follow the same pattern, with the simultaneous appearance of $\alpha$ and $\beta$ ' polymorphic forms followed with 
the transition of the $\alpha$ polymorphs into the more stable packing of $\beta$ '. In all three states, the peak corresponding to $\beta$, polymorphic form increases in magnitude into the detriment of the one corresponding to the metastable $\alpha$ form, whereas the same trend is observed in WAXD. This transition was more enhanced during the isothermal crystallization in the case of milk fat in all three states: AMF, CAMF and WCAMF.

Having no changes during various processing of the fat, such as emulsification and whipping, is of particular industrial importance as it could help predicting and regulating the properties of the final product which are influenced by the fat phase (e.g. texture) only by investigating the bulk fat system attributes. Therefore, the presented methodology and results could facilitate the improvement of partially crystalline $\mathrm{O} / \mathrm{W}$ emulsions and whipped products (e.g. whipped cream, whipped topping).

\section{ACKNOWLEDGEMENT}

The authors would like to acknowledge PURATOS NV (Grant number: 26092012) for financial support.

\section{REFERENCES}

[1]. Zhang, L., Muramoto, H., Ueno, S., \& Sato, K. (2011). Crystallization of Fully Hydrogenated and Interesterified Fat and Vegetable Oil. Journal of Oleo Science, 60, 287-292.

[2]. Kalnin, D., Quennesson, P., Artzner, F., Schafer, O., Narayanan, T., \& Ollivon, M. (2004). Monitoring both fat crystallization and self-assembly of sodium caseinate in model emulsions using synchrotron X-ray diffraction. Progress in Colloid and Polymer Science, 126, 139-145.

[3]. Rousseau, D., Hodge, S. M., Nickerson, M. T., \& Paulson, A. T. (2005), Regulating the $\beta^{\prime} \rightarrow \beta$ Polymorphic Transition in Food Fats. Journal of the American Oil Chemists' Society, 82, 7-12.

[4]. Fauzi, S. H. M., Abd Rashid, N., \& Omar, Z. (2013). Effects of chemical interesterification on the physicochemical, microstructural and thermal properties of palm stearin, palm kernel oil and soybean oil blends. Food Chemistry, 137, 8-17.

[5]. Goff, H. D. (1997). Instability and Partial Coalescence in Whippable Dairy Emulsions. Journal of Dairy Science, 80, 2620-2630.

[6]. Goff, H. D. (2002). Ice Cream. In P. F. Fox, \& P. L. H. McSweeney (Eds.). Advanced Food Chemistry 1. Proteins (pp.1063-1082), 3rd ed. New York: Kluwer Academic.

[7]. Walstra, P. (1999). Dairy Technology: Principles of Milk Properties and Processes, New York: Marcel Dekker.

[8]. Piska, I., Zarubova, M., Louzecky, T., Karami, H., \& Filip, V. (2006). Properties and crystallization of fat blends. Journal of Food Engineering, 77, 433-438.

[9]. Anihouvi, P. P., Blecker, C., Dombree, A., \& Danthine, S. (2012). Comparative Study of Thermal and Structural
Behavior of Four Industrial Lauric Fats. Food and Bioprocess Technology, 6, 3381-3391.

[10].Zhao, Q., Zhao, M., Wang, J., Wang, C., \& Yang, B. (2008), Effects of sodium caseinate and whey proteins on whipping properties and texture characteristics of whipped cream. Journal of Food Process Engineering, 31, 671-683.

[11].Hayati N. I., Che Man, Y. B., Tan, C. P., \& Aini, I. N. (2009). Thermal behavior of concentrated oil-in-water emulsions based on soybean oil and palm kernel olein blends. Food Research International, 42, 1223-1232.

[12].Anihouvi, P. P., Danthine, S., Kegelaers, Y., Dombree, A., \& Blecker, C. (2013). Comparison of the physicochemical behavior of model oil-in-water emulsions based on different lauric vegetal fats. Food Research International, 53, 156-163.

[13].Danthine S. (2012), Physicochemical and structural properties of compound dairy fat blends. Food Research International, 48, 187-195.

[14].Jensen,R.G., Ferris, A. M., \& Lammi-Keefe, C. J. (1991).The composition of milk fat. Journal of Dairy Science, 74, 3228-3243.

[15].Christie, W. W. (1995). Composition and structure of milk lipids. In P. F. Fox (Ed.), Advanced Dairy Chemistry (pp. 1-28), 2nd ed. London: Chapman \& Hall.

[16].Lopez, C., Lavigne, F., Lesieur, P., Bourgaux, C., \& Ollivon, M. (2001). Thermal and Structural Behavior of Milk Fat. 1. Unstable Species of Anhydrous Milk Fat. Journal of Dairy Science, 84, 756-766.

[17].Wiking, L., De Graef, V., Rasmussen, M., \& Dewettinck, K. (2009). Relations between crystallisation mechanisms and microstructure of milk fat. International Dairy Journal, 19, 424-430.

[18].Tomaszewska-Gras, J. (2013). Melting and crystallization DSC profiles of milk fat depending on selected factors. Journal of Thermal Analysis and Calorimetry, 113, 199-208.

[19].Lopez, C., Bourgaux, C., Lesieur, P., Bernadou, S., Keller, G., \& Ollivon, M. (2002). Thermal and Structural Behavior of Milk Fat 3. Influence of Cooling Rate and Droplet Size on Cream Crystallization. Journal of Colloid and Interface Science, 254, 64-78.

[20].Fredrick, E., Van de Walle, D., Walstra, P., Zijtveld, J. H., Fischer, S., Van der Meeren, P., \& Dewettinck, K. (2011). Isothermal crystallization behaviour of milk fat in bulk and emulsified state. International Dairy Journal, 21, 685-695.

[21].Truong, T., Bansal, N., Sharma, R., Palmer, M., \& Bhandari, B. (2014). Effects of emulsion droplet sizes on the crystallisation of milk fat. Food Chemistry, 145, 725-735.

[22].Mulder, H., \& Walstra, P. (1974). The Milk Fat Globule. Emulsion Science as Applied to Milk Products and Comparable Foods, Wageningen: Pudoc.

[23]. Walstra, P., (1995). Physical chemistry of milk fat globules. In P. F. Fox (Ed.), Advanced Dairy Chemistry 2: Lipids (pp. 131-178), 2nd ed., London: Chapman \& Hall.

[24].Campbell, S. D., Goff, H. D., \& Rousseau, D. (2004). Modeling the Nucleation and Crystallization Kinetics 
of a Palm Stearin/Canola Oil Blend and Lard in Bulk and Emulsified Form. Journal of the American Oil Chemists' Society, 81, 213-219.

[25].Katsuragi, T., Kaneko, N., \& Sato, K. (2001). Effects of addition of hydrophobic sucrose fatty acid oligoesters on crystallization rates of $n$-hexadecane in oil-in-water emulsions. Colloids and Surfaces B: Biointerfaces, 20, 229-237.

[26]. Vanderghem, C., Danthine, S., Blecker, C. \& Deroane, C. (2007), Effect of proteose-peptone addition on some physico-chemical characteristics of recombined dairy creams, International Dairy Journal, 17, 889-895.

[27].Foubert, I., Fredrick, E., Vereecken, J., Sichien, M., \& Dewettinck, K. (2008). Stop-and- return DSC method to study fat crystallization. Thermochimica Acta, 471, 7-13.

[28].McClements, D. J. (1999). Food Emulsions: Principles, Practice and Techniques. Florida: CRC Press.

[29].Petrut, R. F., Danthine, S., Blecker, C., (2015), Assessment of partial coalescence in whippable oil-inwater food emulsions, Advances in Colloid and Interface Science, 229, 25-33;

[30]. Walstra, P. (1967). On crystallization habit in fat globules. Netherlands Milk and Dairy Journal, 21, 166191.

[31]. Vanapalli, S. A., Palanuwech, J., \& Coupland, J. N. (2002). Stability of emulsions to dispersed phase crystallization: effect of oil type, dispersed phase volume fraction, and cooling rate. Colloids and Surfaces A: Physicochemical and Engineering Aspects, 204, 227-237.

[32].Walstra, P., \& van Beresteyn, E.C.H. (1975). Crystallization of milk-fat in emulsified state, Netherlands Milk and Dairy Journal, 29, 35-65.

[33]. McClements, D. J., Dungan, S. R., German, J. B., Simoneau, C., \& Kinsella, J. E. (1993). Droplet Size and Emulsifier Type Affect Crystallization and Melting of Hydrocarbon-in-Water Emulsions. Journal of Food Science, 58, 1148-1151.

[34].Huck-Iriart, C., Candal., R. J., \& Herrera, M. L. (2009). Effects of Addition of a Palmitic Sucrose Ester on Low-Trans-Fat Blends Crystallization in Bulk and in Oil-in-Water Emulsions. Food Biophysics, 4, 158-166.

[35].Cornacchia, L., \& Roos, Y. H. (2011). Lipid and water crystallization in protein-stabilised oil-in-water emulsions. Food Hydrocolloids, 25, 1726-1736.

[36].Larsson, K. (1972). Molecular Arrangements in Glycerides. Fette Seifen Anstrichmittel, 74, 136-142.

[37].Larsson, K. (1994). Lipids - Molecular Organization, Physical Functions and Technical Applications. Dundee: The Oily Press.

[38].Lopez, C., Lesieur, P., Keller, G., \& Ollivon, M. (2000). Thermal and Structural Behavior of Milk Fat 1. Unstable Species of Cream. Journal of Colloid and Interface Science, 229, 62-71.

[39].Sato, K. (2001). Crystallization behaviour of fats and lipids - a review. Chemical Engineering Science, 56, 2255-2265.

[40].van Aken, G. A., \& Visser, K. A. (2000). Firmness and crystallization of milk fat in relation to processing conditions. Journal of Dairy Science, 83,1919-1932.
[41].Konno, M., Iwasawa, A., Isogai, T., Tanaka, L., Murakami, M., \& Shiota, M. (2012). Effect of Shearing on Crystallization of Palm Oil-Based Fat Blends. Food Science and Technology Research, 18, 375-382.

[42].Sato, K., \& Ueno, S. (2011). Crystallization, transformation and microstructures of polymorphic fats in colloidal dispersion states. Current Opinion in Colloid \& Interface Science, 16, 384-390.

[43]. Yamoneka, J., Malumba, P., Blecker, C., Gindo, M., Richard, G., Fauconnier, M. L., Lognay, G. \& Danthine, S. (2015), Physicochemical properties and thermal behaviour of African wild mango (Irvingia gabonensis) seed fat, LWT - Food Science and Technology, 64, 989-996.

[44].Sonoda, T., Takata, Y., Ueno, S., \& Sato, K. (2004).DSC and Synchrotron-Radiation X-ray Diffraction Studies on Crystallization and Polymorphic Behavior of Palm Stearin in Bulk and Oil-in-Water Emulsion States. Journal of the American Oil Chemists' Society, 81, 365-373. 